\title{
URETROCISTOPEXIA SIN SUTURAS COMO TRATAMIENTO DE INCONTINENCIA URINARIA EN PACIENTES DEBILITADAS
}

\author{
Doctor Delfino Gallo*
}

Este es un breve informe sobre un método estudiado en la Clínica Ginecológica del Hospital Civil dependiente de la Universidad de Guadalajara, México.

Se funda en un principio completamente nuevo: a través de una pequeñísima incisión suprapúbica se despega digitalmente la uretra y vejiga, lo que permite su desplazamiento y reacomodo. Dichas estructuras se sostienen luego por medio de un clamp permanente que mediante una rama introducida en la vagina las apoya contra el pubis óseo en la posición corregida.

El clamp permanece "in situ" hasta lograr la formación del tejido cicatrizal que asegure la conservación de la buena posición de los órganos (aproximadamente dos semanas).

Para practicar esta intervención es indispensable el uso del instrumento especialmente diseñado (fig. 1).

Los tiempos operatorios son como sigue:

Después de colocar una sonda de Foley se hace bajo anestesia por infil- tración una incisión mediana suprapúbica de $4 \mathrm{~cm}$. de longitud (fig. 2). Se incinde la piel, tejido celular y aponeurosis.

Se introduce el dedo índice y mediante cuidadosos movimientos se separan

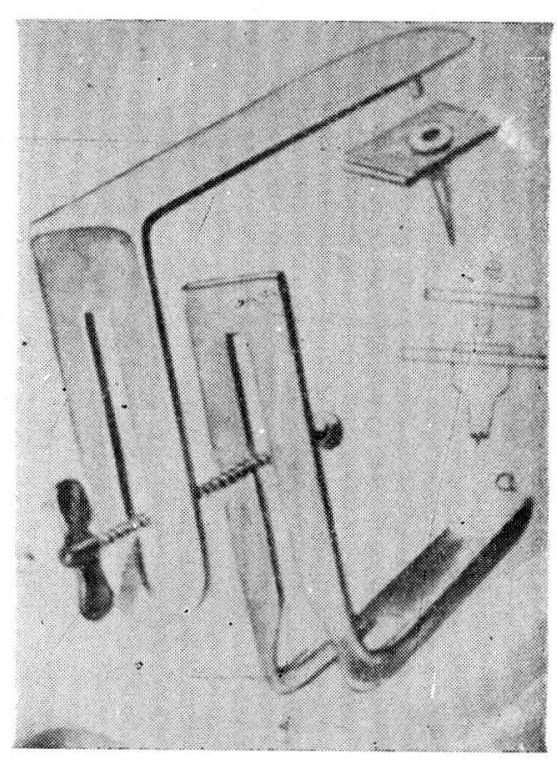

Figura 1

* Profesor de Ginecología de la Facultad de Medicina de la Universidad de Guadalajara (México). 
los músculos piramidales y se penetra en el espacio de Retzius; se despega la vejiga del pubis y luego la uretra hasta llegar profundamente hasta cerca del meato externo (fig. 3). Se tapona el despegamiento por diez minutos con una gasa mojada en solución salina caliente (fig. 4).

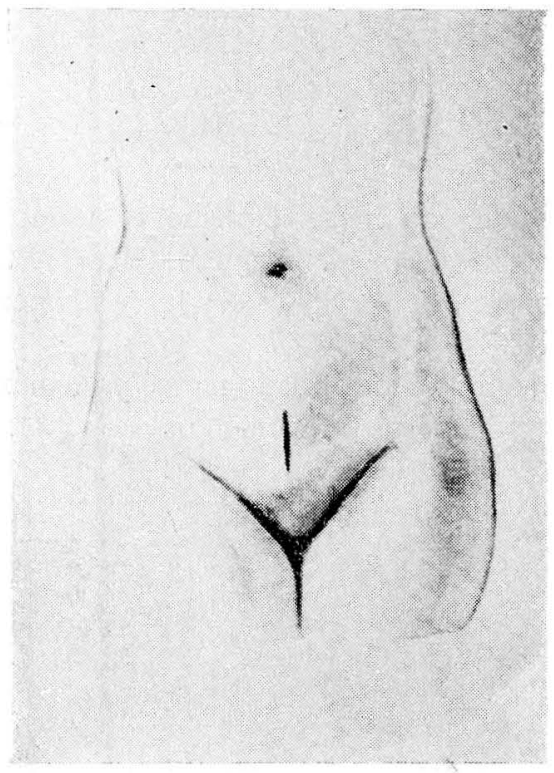

Figura 2

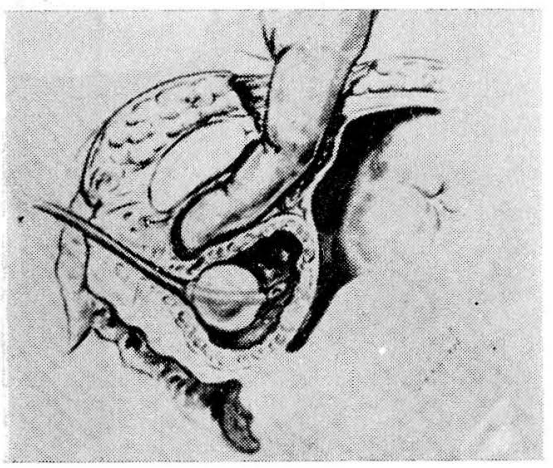

Figura 3
Se retira la gasa y se instila en la cavidad del despegamiento una solución de trombina tópica (fig. 5), con propósitos de hemostasia y para promover ad-

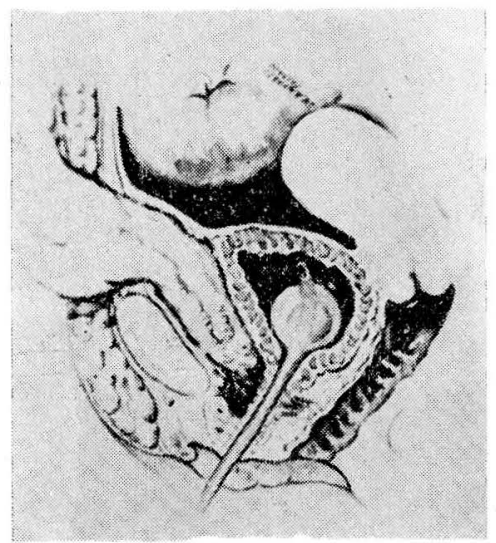

Figura 4

herencia de las estructuras blandas contra el pubis óseo. Se cierra la fascia con puntos de sutura.

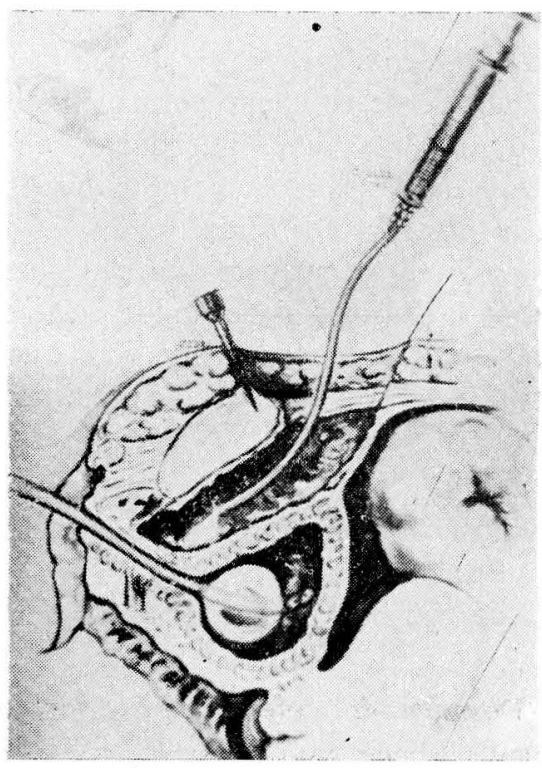

Figura 5 
Se coloca el clavo del clamp en el borde superior del pubis y se cierra la piel. Dejando el extremo del clavo exteriorizado, se le fija provisionalmente la piel con esparadrapo.

Se adapta el clavo a la pieza externa del clamp y se introduce la pieza vaginal, uniendo ambas porciones mediante el tornillo pero sin apretarlo.

Se acercan paulatinamente ambas piezas hasta comprobar por el tacto que la cara anterior de la vagina ha quedado pegada al hueso pubis; se aprieta el tornillo, quedando desde entonces el compresor sostenido por su propia presión con los tejidos.
El clamp y la sonda se dejan colocados por dos semanas (fig. 6).

Este procedimiento tiene la ventaja de ser extraordinariamente sencillo: Sólo exige anestesia local completada por momentos con inhalaciones de gas o con inyección intravenosa de pequeñas dosis de barbitúricos de acción rápida, y se realiza en sólo unos minutos. No hemos querido emplearlo sino en incontinencia de mediana severidad, y en aquellas enfermas que se encuentran en malas condiciones físicas para tolerar una operación amplia.

Hasta el momento no hemos asociado el uso de compresor con uretrocistorrafia en la misma sesión operatoria.

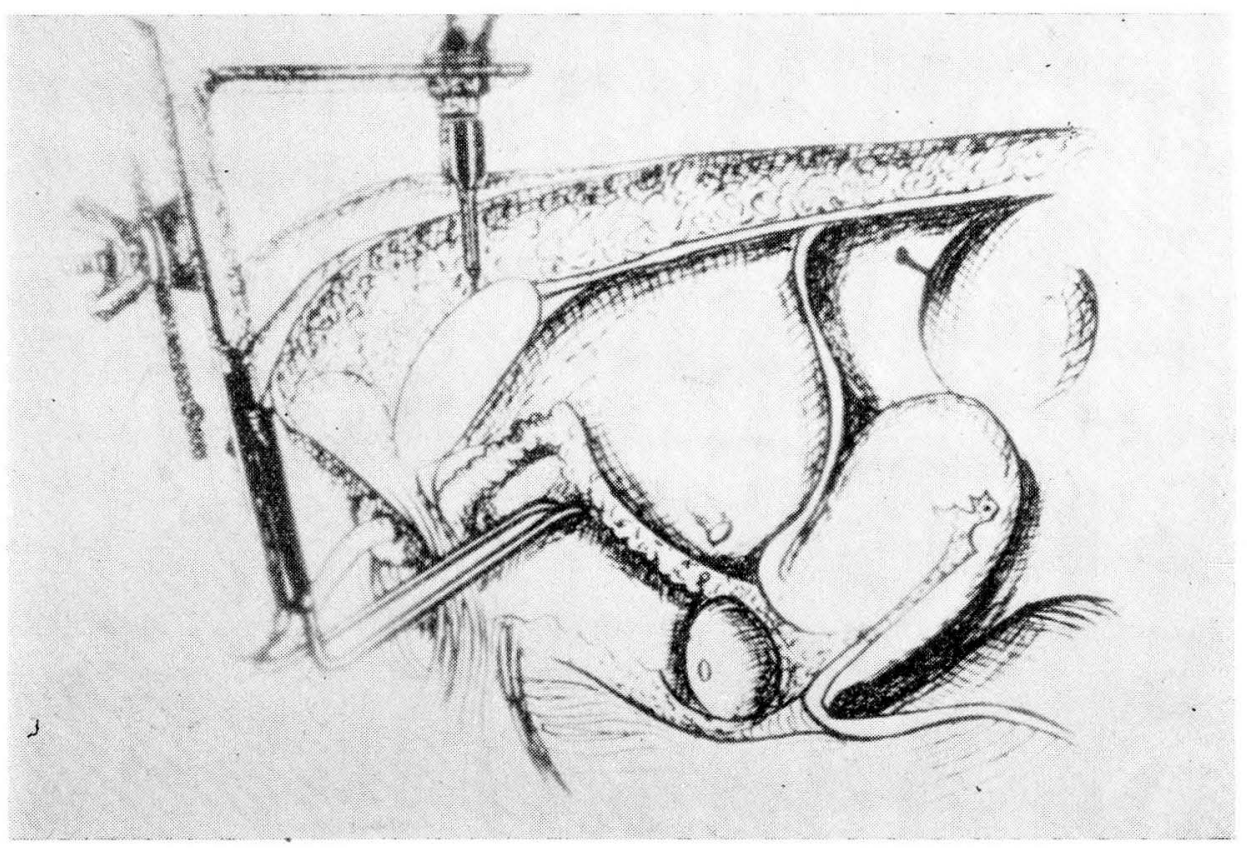




\section{RESUMEN Y CONCLUSIONES}

1. Se presenta un procedimiento de Uretrocistopexia sin suturas fundado en un principio completamente nuevo.
2. La indicación de su uso está en las pacientes que podrían soportar otro procedimiento.

3. Se obtuvo continencia muy aceptable en 4 casos de seis intervenciones. 